American J. of Engineering and Applied Sciences 2 (1): 96-104, 2009

ISSN 1941-7020

(C) 2009 Science Publications

\title{
A Study of the Effect of Infilled Brick Walls on Behavior of Eccentrically Braced Frames Using Explicit Finite Elements Method
}

\author{
Amir Saedi Daryan, Masood Ziaei, Ali Golafshar, \\ Akbar Pirmoz and Mohammad Amin Assareh \\ Faculty of Civil Engineering, \\ K.N. Toosi University of Technology, P.O. Box 15875-4416, Tehran, Iran
}

\begin{abstract}
Problem statement: Eccentrically Braced Frames (EBFs) are usually infilled by masonry walls, but in common design, the stiffness and lateral resistance of these walls is ignored. Considering the results of carried out tests and studies, it seems that infilled masonry walls have a significant influence on the stiffness and the strength of EBFs. Since experimental test of total frame with infilled brick wall is a very expensive and time consuming process, proper numerical models which can precisely simulate the behavior of EBFs considering the effects of infilled brick wall are necessary. Approach: In this study, a proper model is made using explicit finite elements method to study the behavior of EBFs with infilled masonry wall. Because of complicated mechanical and geometrical properties of masonry walls and also because of the interaction between steel frame and masonry wall, this model is not easy to obtain. To ensure the ability of the model to precisely simulate the behavior of an EBF with infilled brick wall, initial models were made and the problems were solved comparing the results of experimental test and the results of these initial models. Firstly, material models and some basic principles of explicit finite element algorithm are used and three initial models were made: a model of a brick wall without eccentrically braced steel frame, a model of an EBF without infilled brick wall and finally a model of an EBF with infilled brick wall. Results: Using these three initial models, constitutive model for masonry and steel material and also the proper elements for modeling the behavior of mortar is obtained. Studies showed that good prediction of the behavior of a system consisting of EBF and masonry wall is possible, by minimizing the kinematical energy and using a special time scaling of explicit finite element model. Conclusion: After verifying the finite element models, the influence of masonry infilled wall on the behavior of eccentrically braced frames is studied. This investigation showed that in general, the presence of masonry wall increases the yield strength and the elastic range in the force-displacement curves. But the plastic behavior of the frame is deteriorated and due to fragile behavior of masonry materials, the total system of steel frame and masonry wall has a significant strength fall when the elastic range is passed.
\end{abstract}

Key words: Eccentrically braced frame, infilled brick wall, explicit finite element method, stiffness

\section{INTRODUCTION}

Seismic design of structures must satisfy two basic criteria. A structure must have sufficient stiffness to keep deflections below the limit of non-structural damage during minor seismic events and possess sufficient ductility to prevent collapse in the event of a rare overload which might occur during a major earthquake. In an eccentrically braced frame, axial forces induced in the braces are transferred either to a column or another brace through shear and bending in a segment of the beam called link beam. These link beams act to dissipate the large amount of input energy of a severe seismic event via material yielding. These frames are usually infilled by masonry walls but in common design, the influence of these walls on the behavior of total frame is ignored. These infilled walls may have a significant influence on the stiffness and the strength of eccentrically braced frames. In a well designed EBF, inelastic action is limited just to the link beam and the other members remain in the elastic range during an earthquake. The existence of a masonry wall may influence the action of link beam, so the behavior of these frames should be studied considering the effects of infilled masonry walls. Although there are several studies about eccentrically braced frames and masonry walls, study about the eccentrically braced frame with infilled wall is rare.

Because of the advances in numerical methods, simulation of complicated real structures became possible. Among the numerical methods, the explicit finite element method is a powerful method for studying and modeling an eccentrically braced frame with infilled masonry wall. In this article a finite

Corresponding Author: Amir Saedi Daryan, K.N. Toosi University of Technology, P.O. Box 15875-4416, Vali Asr St., Mirdamad Blvd., Tehran, Iran Tel: +982122749398 Fax: +982122749399 
element model for an eccentrically braced steel frame is made and compared to the same frame which has the infilled wall. ABAQUS finite element program is used for parametric modeling of specimens. Firstly, the analysis of the frame without masonry wall was carried out by standard method and the model was verified using the results of experimental tests. Then the EBF model was made with and without infilled masonry wall and the analysis was done by explicit finite element method and the results were compared to the results of experimental tests to assure the ability of the explicit finite element method for simulating the complicated mechanical and geometrical properties and also the interaction between masonry and steel material in the frame. After verifying the models, final model was made to study the behavior of an eccentrically braced frame with infilled brick wall.

Popov and Kasai ${ }^{[1]}$ studied the effects of axial force on the behavior of link beams with different lengths. Douglas and Foutch ${ }^{[2]}$ conducted a test on a full-scale six-storey eccentrically braced dual frame to study the behavior of real structure. Popov and Engelhardt ${ }^{[3]}$ studied the design method for eccentrically braced frames. They concluded that capacity design principles should be used as an overall design basis for EBFs. Ramadan and Ghobarah $^{[4]}$ proposed a finite element model for the link beam in eccentrically braced frames. This model was used to evaluate the behavior of link beam under cyclic displacements. The results have a good agreement with the results of experimental tests. They developed the finite element model in 1991 using ADINA language code and concluded that this model can be used as a powerful instrument for study the respond of link beam to different loadings like increasing monotonic loading, cyclic loading and cyclic loading in combination to axial force ${ }^{[5]}$. Popov and Engelhardt ${ }^{[6]}$ carried out an experimental study on eccentrically braced frames with long links connected to columns. The aims of the study were to investigate possible instabilities of the beam located outside of the link beam, determine the yielding mechanisms and prevalent failure modes in long link beams, study the rotation capacity and ultimate strength of long links and finally study the effect of using stiffeners on local buckling delay in long link beams ${ }^{[6]}$. Popov and Ricles $^{[7]}$ proposed a formulation for link beam modeling under accidental inelastic cyclic loading. To verify the models made in this article, two experimental tests were selected. The first experimental test was the test carried out by Bruneau and Berman ${ }^{[8]}$.

\section{MATERIALS AND METHODS}

Details of Bruneau and Berman test: Bruneau and Berman ${ }^{[8]}$ studied the effect of using box section as the link beam in eccentrically braced frames. In usual design, wide flange sections are used for link beams, but since it is impossible to provide lateral bracing in bridges to prevent lateral-torsion buckling, box section was used to eliminate the need for the lateral bracing, because box sections have significant torsional strength. This test was selected for verifying the finite element models. The test setup is shown in Fig. 1.

FE Model and material properties: Shell elements were used to make the frame model. As it can be seen in Fig. 1, the frame is simply supported and the load is applied through a beam which is connected to the frame by a hinge. For simulating the base support condition and load applying method, the connection of columns to the base is modeled in a way to act like a hinge. The same condition is built at the top of the columns to simulate the exact load applying method used in the experimental test. The finite element model is shown in Fig. 2a. To prevent local buckling, stiffeners are placed around the beam since box section is used as the beam in this frame. The model is analyzed using standard method.

Verifying the model: A comparison is made between the results of the experimental test and the results of finite element model analysis which is shown in Fig. 3. As it can be seen, there is a good agreement between the results. Finite element model had the ability to predict the peak point and also the initial stiffness of the curve. Deformed frame after the analysis is shown in Fig. 2b.

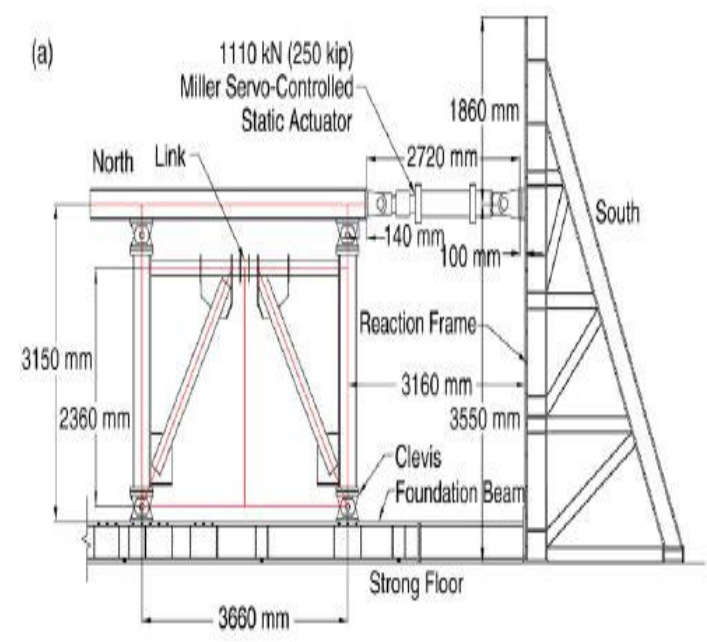

Fig. 1: Test setup used by Bruneau and Berman ${ }^{[8]}$ 


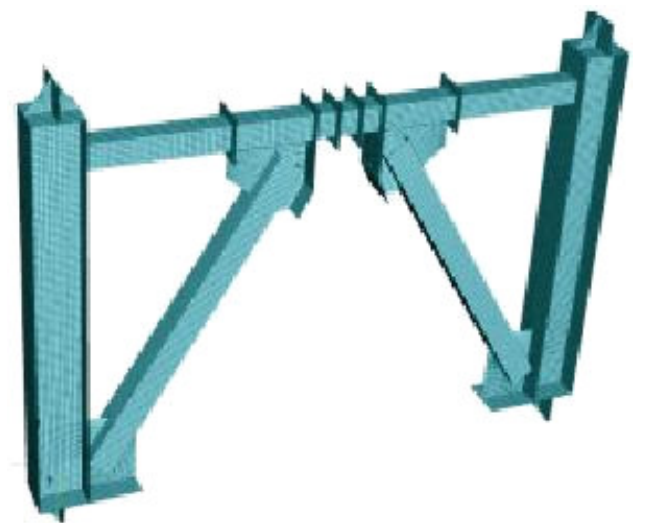

(a)

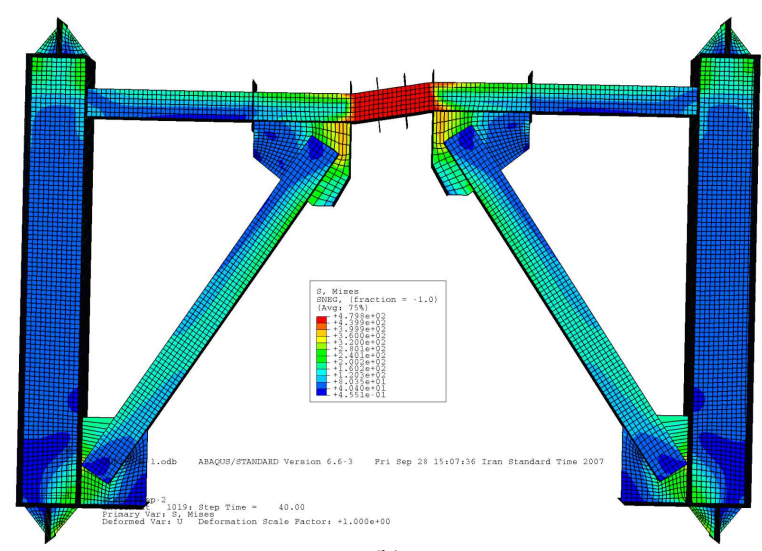

(b)

Fig. 2: Finite element model of the eccentrically braced frame, (a): Before analysis, (b): After analysis

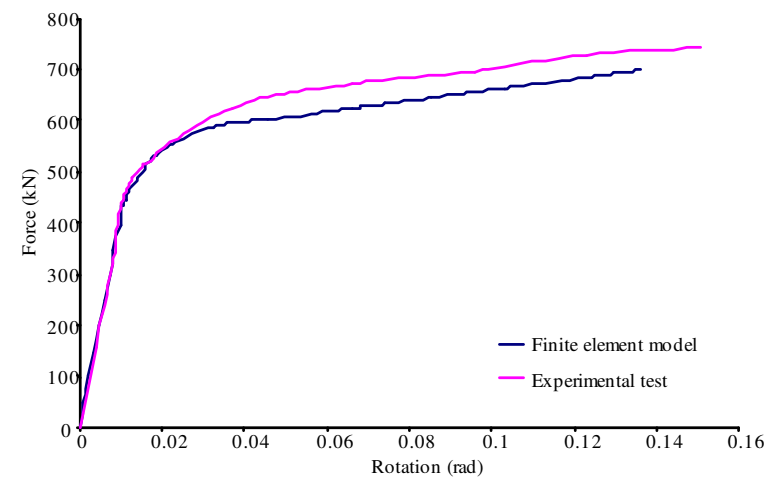

Fig. 3: Force-displacement obtained by experimental test of Bruneau and Berman ${ }^{[8]}$

Masonry panel: The complex mechanical behavior of masonry structures is the result of their nonhomogenous and brittle material properties, as well as its geometric intricacy: masonry is composed of aligned, uniformly dispersed units connected by a regular array of bed and head mortar joints. These mortar joints are the weakness of the assembly and exhibit notable material nonlinearity and significantly influence the response of masonry. The nonlinear characteristics of the mortar joints initially result from the nonlinear deformation characteristics of the joints under shear and compression but are exaggerated by local failure, opening-closing, dilatancy and slip of the joints.

Two mechanical approaches, macro- and micromodeling, have been adopted by researchers to formulate an appropriate constitutive description of masonry structures. The macro-modeling approach neglects the distinction between units and mortar joints by taking into account the effect of discrete joints in an average sense through homogenization techniques such as those presented by ${ }^{[9,10]}$. Generally, this approach is recommended for the analysis of large masonry structures because of the inability to exert detailed stress analysis and capture the various failure mechanisms of masonry assemblages. Gambarotta et al. ${ }^{[11]}$ adopted a refined approach in which the wall was simulated as an equivalent stratified medium made up of layers representative of the mortar bed joints and of the units and head joints, respectively.

Alternately, the micro-modeling approach is a computationally intensive approach. A large number of elements are required because the masonry structure is modeled as a discontinuous assembly of blocks connected by appropriate discrete joints. The joints are simulated by appropriate constitutive interface elements so that considerations such as the initiation of fracture, propagation of cracks and sliding at interfaces with different levels of refinement of the assemblage can be taken into account. Therefore, a more realistic and rigorous analysis can be expected since it allows locating exact joint positions and adopting appropriate constitutive models for the blocks and interfaces. Considering the above concepts and the accuracy needed in this study for simulating the initiation of failure, crack propagation and slippage in different surfaced, the micro method was selected for modeling the behavior of infilled brick wall.

Masonry shear walls are generally tested in the lab using quasi-static loading history in order to gain better understanding of the failure pattern and deformation characteristics including measure of ductility. As such they are modeled using static perturbation finite element modeling techniques based on implicit methods. Such finite element analyses of masonry walls in general, although have provided much insight into the behavior of masonry shear walls, have been 
regarded as too cumbersome and inefficient in terms of the time taken for the analysis as well as the complexities of the modeling strategies. These conventional implicit techniques require solution of equilibrium equations containing full stiffness matrix of the structure, as such they are very time consuming. Furthermore, as the masonry cracks the stiffness matrix tend to become ill conditioned posing a convergence problem. This study presents a computationally efficient explicit finite element modeling technique that is capable of simulating highly nonlinear events. The explicit finite element modeling technique never requires a fully assembled system stiffness matrix; rather it solves for the internal variables using the theory of dynamic wave propagation in solids. Although explicit technique is more suitable for high dynamic events such as impact, quasi-static load tests could also be simulated if due care is taken to minimize the kinetic energy due to rapid cracking/load shedding. As iterations are not performed, much smaller increments of the applied load are required for the explicit technique to provide acceptable results. Converged solutions obtained from this technique are based on satisfaction of the global energy equilibrium equations.

Critical time increment: In time integration methods, choosing a proper time increment is definitely important. Small time steps are necessary to obtain accurate and stable responses.

ABAQUS/EXPLICIT generally requires 10,000$1,000,000$ increments to achieve converged solutions, but the computational cost per increment is generally relatively small. For accuracy, the time increment was kept quite small. Maximum time increment used by the explicit solver related to the stability limit of the structure globally is calculated from the natural frequency corresponding mode shapes of a dynamic system. The loading time was increased up to 100 times the period of the lowest mode. By artificially increasing the step time the velocities and the kinetic energy were minimized. In the followings, to verify the masonry infilled wall models, the experimental tests carried out by ${ }^{[14]}$ were selected and the finite element models were made according to the specimens tested in this experimental study and the models were analyzed using explicit finite element method.

In total, seven tests were conducted on the wall specimens made of masonry materials. The sizes of all specimens were the same and the only difference in the tests was the applied vertical load. Geometrical properties and test installation is shown in Fig. 4. Applied vertical load for every specimen is tabulated in

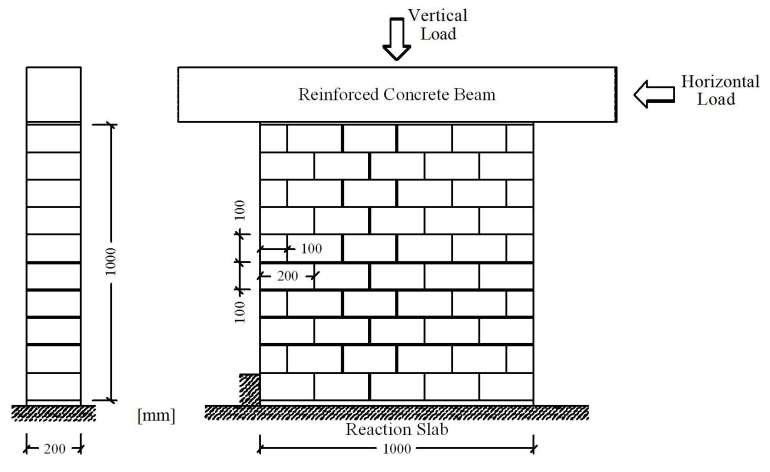

Fig. 4: The properties and the test method used in the experimental tests carried out by ${ }^{[11]}$

Table 1: The values of applied vertical load used in the tests

\begin{tabular}{lc}
\hline Wall designation & Vertical load $(\mathrm{KN})$ \\
\hline SW30.1 & 30 \\
SW30.2 & 30 \\
SW100.1 & 100 \\
SW100.2 & 100 \\
SW200.1 & 200 \\
SW200.2 & 200 \\
SW250.1 & 250 \\
\hline
\end{tabular}

Table 1. To construct the wall specimens, a layer of mortar was poured on the slab at first and then the wall is constructed. Then a concrete beam is installed on the wall and finally measuring instruments were installed on the wall.

The walls were tested after drying. The vertical compression load is applied by a $1000 \mathrm{KN}$ capacity hydraulic actuator using force control method. The rate of loading was $1 \mathrm{KN}$ per second. When the vertical load reached to the specific value, it is kept constant and the lateral load is applied to the specimens by applying small displacements.

Two kinds of elements were used to model masonry panels, eight-node solid elements were used to model the bricks and contact elements were used to simulate the mortar. It was assumed that the panel behaves nonlinearly under applied displacement. The mortar was modeled using interaction element in ABAQUS which allows for small relative slippage in the contact surface. The properties of this element are defined according to the properties of mortar in the experimental test. In the Fig. 5 finite element model and sub-structures are shown. The model meshing was fine enough to obtain accurate results. Material properties used in the test are tabulated in Table 2.

Force-displacement curves and cracking pattern of masonry panels obtained by finite element model is compared to those obtained by the experimental test. Figure 5 shows a comparison between the cracking 
Am. J. Engg. \& Applied Sci., 2 (1): 96-104, 2009

Table 2: material properties of the specimens used in Vitorino tests

\begin{tabular}{llll}
\hline Material & $\begin{array}{l}\text { Poisson } \\
\text { ratio }\end{array}$ & $\begin{array}{l}\text { Ultimate stress } \\
\left(\mathrm{N} \mathrm{mm}^{-2}\right)\end{array}$ & $\begin{array}{l}\text { Modulus of } \\
\text { elasticity }\left(\mathrm{N} \mathrm{mm}^{-2}\right)\end{array}$ \\
\hline Block & 0.2 & 57 & 15500 \\
Material & & $\begin{array}{l}\text { Coefficient } \\
\text { of friction }\end{array}$ & Cohesion \\
Mortar & & 0.62 & 0 \\
Walls & & $\mathrm{Kn}\left(\mathrm{N} \mathrm{mm}^{-3}\right)$ & $\mathrm{Ks}\left(\mathrm{N} \mathrm{mm}^{-3}\right)$ \\
SW30 & & 5.87 & 2.45 \\
SW100 & & 8.08 & 3.37 \\
SW200 & & 11.4 & 4.73 \\
SW250 & & 13 & 5.43 \\
\hline
\end{tabular}

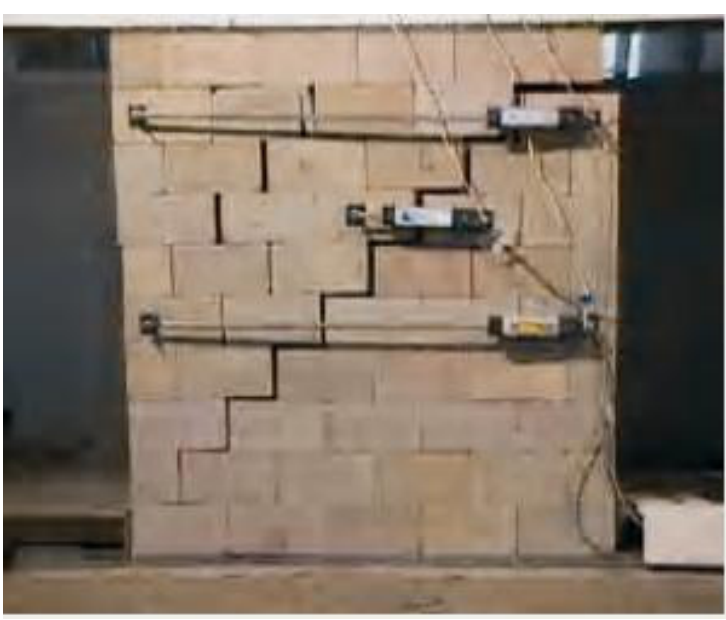

Fig. 5: crack pattern in brick panel

pattern obtained by finite element model and experimental test. Failure modes show the relation between vertical load and crack pattern. In the specimens with fewer vertical loads, the failure of wall is in the form of cracks in the seams and no fracture occurred in the blocks. But in the specimens with higher vertical loads, diagonal cracks appeared and there were some fractures in the blocks. In general, it can be concluded that failure mechanism in wall is in the form of diagonal cracks and fracture of some panels and when the vertical load is increased the probability of block fracture increases. Force-displacement response obtained by finite element modeling and experimental tests is shown in Fig. 6. It can be observed that force-displacement respond curves have good agreement both in elastic and plastic ranges. This agreement shows the ability of explicit finite element to accurately predict the behavior of masonry panels. .The difference between the results of modeling and experimental test in nonlinear range is due to several parameters such as simplifications used in finite element model, defects in experimental tests, residual stress and especially nonlinear constitutive laws used in finite element modeling.
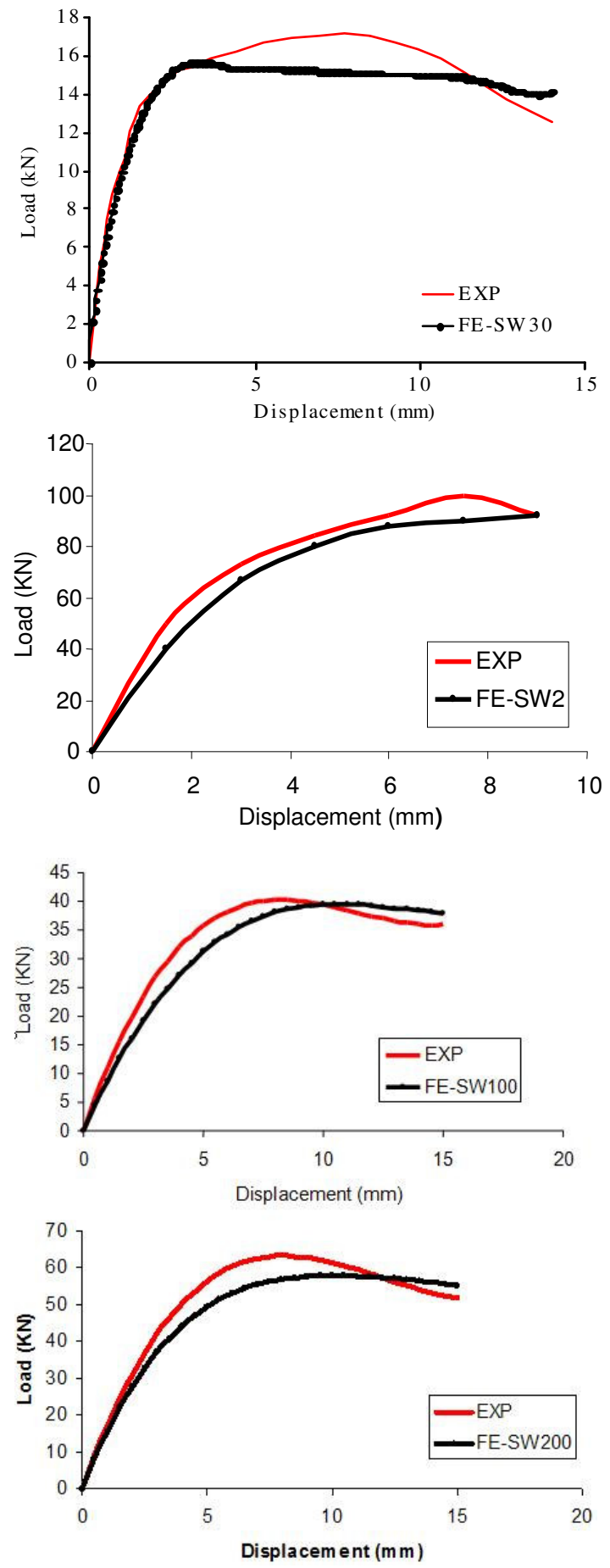

Fig. 6: Force-displacement curves of the tests carried out by ${ }^{[11]}$

Steel frame with infilled brick wall: Considering the prevalent application of masonry material in structures and their determinant role in stiffness and strength of 
structures, many studies have been carried in this field. In some of these studies, masonry panels are investigated separately and in some others, masonry materials are studied as infilled walls surrounded by steel frame (like the real situation of masonry panels in structures). The latter studies present more realistic results and applied forces and cracking pattern are closer to the real behavior of structural frames. For example, experimental tests have been carried out by Moghaddam et $a l^{[12]}$ on steel frames infilled by masonry and concrete walls ${ }^{[12]}$. In this study, the results of this experimental test are used to verify the finite element models. These models are analyzed using explicit finite element method.

Details of the selected experimental test: Moghaddam et al. ${ }^{[12]}$ tested 11 steel frame specimens infilled by masonry and concrete walls under cyclic loading. One of these specimens which is a steel frame with masonry wall is selected to verify finite element models. The properties of this specimen are shown in Fig. 7.

Finite element model and material properties: Brick panel is modeled using eight-node solid elements and contact elements are used to model the mortar. It is assumed that the panel behaves nonlinear under applied displacement. The mortar between the bricks is modeled using interaction element in ABAQUS which allows for little relative slippage in the contact surface. The properties of this element are defined according to the properties of mortar in the test specimens. Steel frame modeling is done using shell elements. To obtain accurate results, the meshing of finite element model was fine enough. Material properties of the experimental test are tabulated in Table 3.

Finite element verification: Force-displacement curves obtained by experimental test and finite element model are compared in Fig. 8. Initial stiffness and ultimate

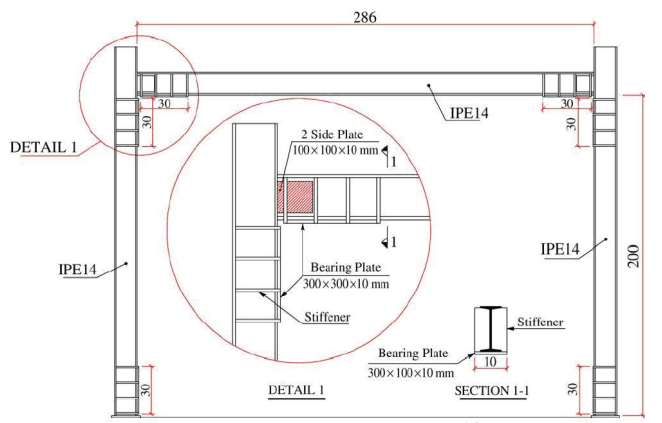

Fig. 7: Specimen properties tested by ${ }^{[12]}$ load in the two curves are close to each other which verify that explicit finite element method is precisely capable of simulate the behavior of masonry walls. Crack pattern in the finite element model is diagonal which is similar to those observed in experimental test carried out by Moghaddam et al. ${ }^{[12]}$.

Final finite element models: Using the initial finite element models, the capability and the accuracy of explicit finite element method to precisely simulate the behavior of steel frames with masonry wall is verified. Then six eccentrically braced frame finite element models are made. The masonry wall properties are according to Table 2. Finite element model of specimen SMI3.4 before analysis is shown in Fig. 9. It should be

Table 3: Material properties of the experimental test conducted by

\begin{tabular}{|c|c|c|c|}
\hline \multirow{2}{*}{$\begin{array}{l}\text { Material } \\
\text { of }\end{array}$} & Yield & Ultimate & Modulus \\
\hline & $\begin{array}{l}\text { Stress } \\
\left(\mathrm{N} \mathrm{mm}^{-2}\right)\end{array}$ & $\begin{array}{l}\text { stress } \\
\left(\mathrm{N} \mathrm{mm}^{-2}\right)\end{array}$ & $\begin{array}{l}\text { elasticity } \\
\left(\mathrm{N} \mathrm{mm}^{-2}\right)\end{array}$ \\
\hline Steel & 210 & 400 & $1.7 * 105$ \\
\hline
\end{tabular}

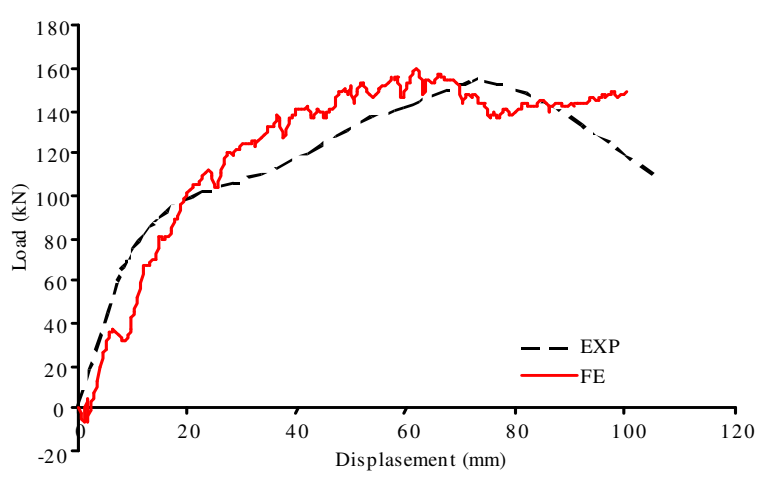

Fig. 8: Force-displacement obtained by experimental test carried out by ${ }^{[12]}$

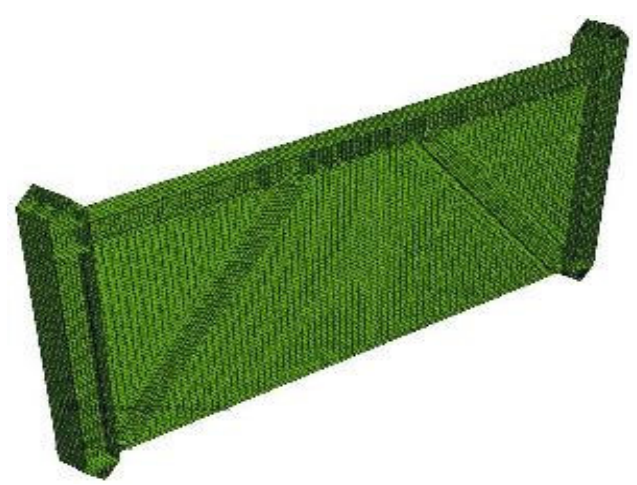

Fig. 9: Finite element model of specimen SMI3.4 

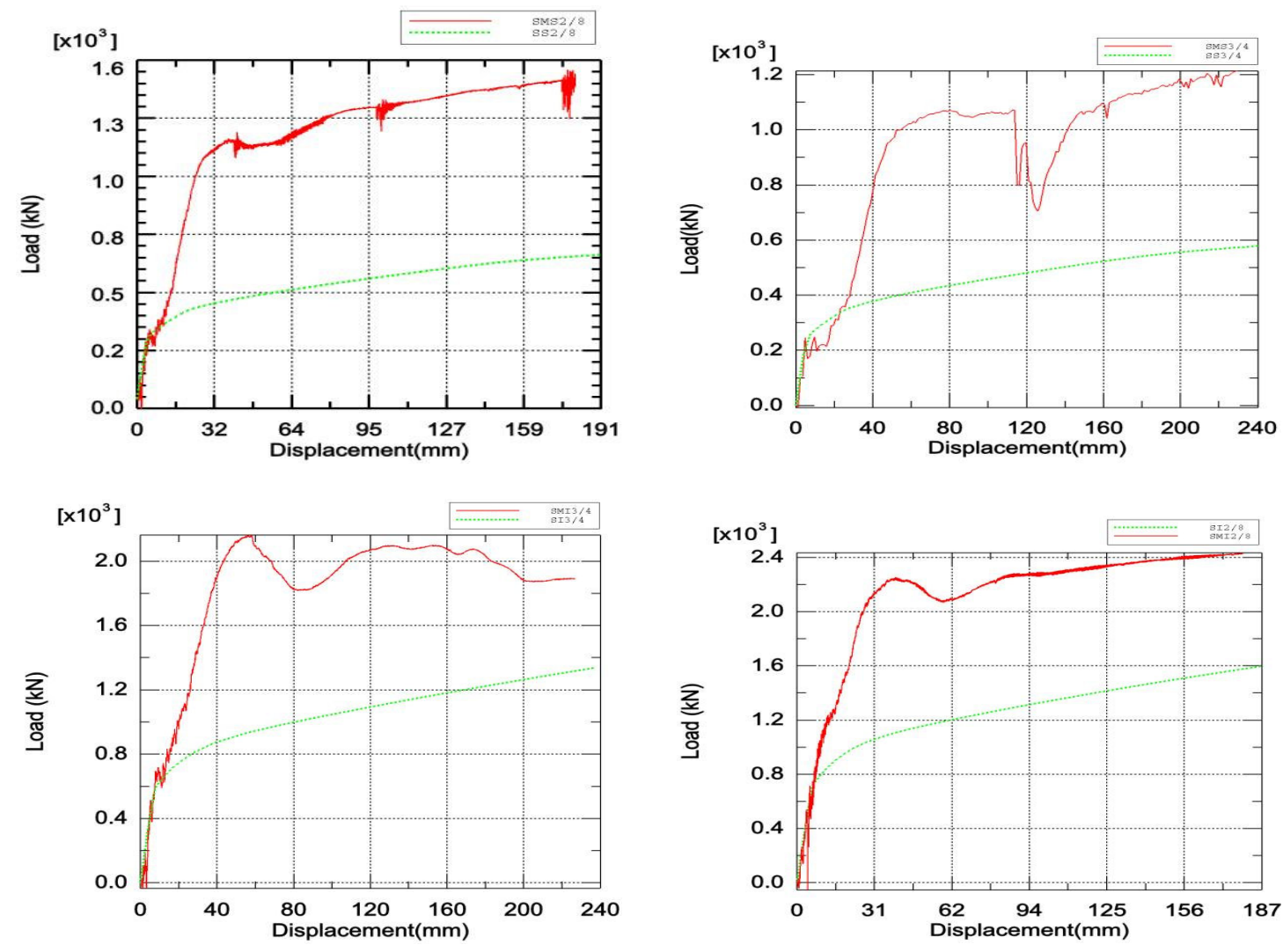

Fig. 10: A comparison between force-displacement curves of frames with and without masonry wall

cases. In the first case, the masonry wall is not braced in out of plane direction (SML3.4, SML2.8). In the second case, the brick wall is braced in out of plane direction, as it is required in seismic provisions (SML3.4*, SML2.8*).

Results obtained from analysis of the models: The results obtained from the analysis of models are shown in Fig. 10 as force-displacement curves. In Fig. 10, force-displacement curves are shown for every frame model with and without masonry wall.

If the collapse limit of the structures is assumed to be the drift equal to $2 \%$ of structure height, as it is obvious from the figures, the masonry wall significantly affects the behavior of EBF. When the masonry wall does not exist, the frame dissipates a little part of input energy in elastic range and most of it in plastic range and so the frame has a full ductile behavior. But the behavior of the frames changes when the infilled brick wall exists. The presence of masonry wall affects both strength and lateral displacement of eccentrically braced frame. The stiffness and the strength of frame in elastic range increase significantly, but when the total system enters in plastic mode, after a little increase, the strength of frame decreases significantly due to fragile behavior of masonry wall. Because of principle cracking of masonry wall or sometimes collapse of it as it is shown in Fig. 11, steel frame and masonry wall do not as a united system and the increase in strength observed after the mentioned fall is only because of steel frame. To compare the results of steel frames with and without masonry wall, it should be said that in the case where masonry wall exists the displacement in which the total system yields is higher, but since the plastic range in force-displacement force is decreased significantly, the total displacement capacity of the frame is decreased.

As it can be shown in Fig. 11, the rotation capacity of the frame with brick wall is significantly decreased compared to the rotation capacity in bare steel frame. Except two frames, the fracture of masonry wall occurred before the link beam can reach the required rotation capacity of shear link beams ( $0.08 \mathrm{rad})$ and this shows that the frames are not ductile enough. 

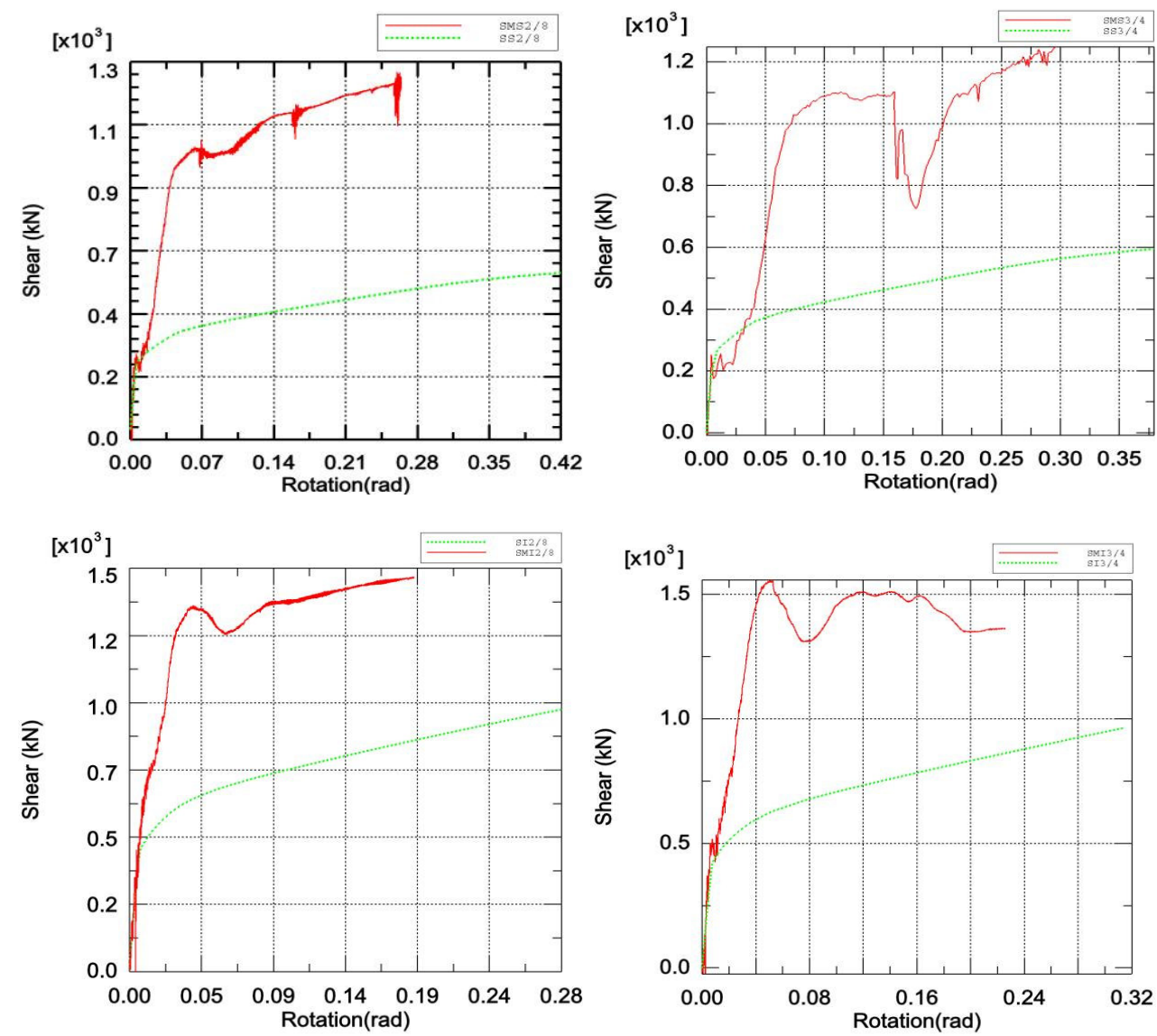

Fig. 11: A comparison between the rotation of link beams in the frames with and without link masonry wall
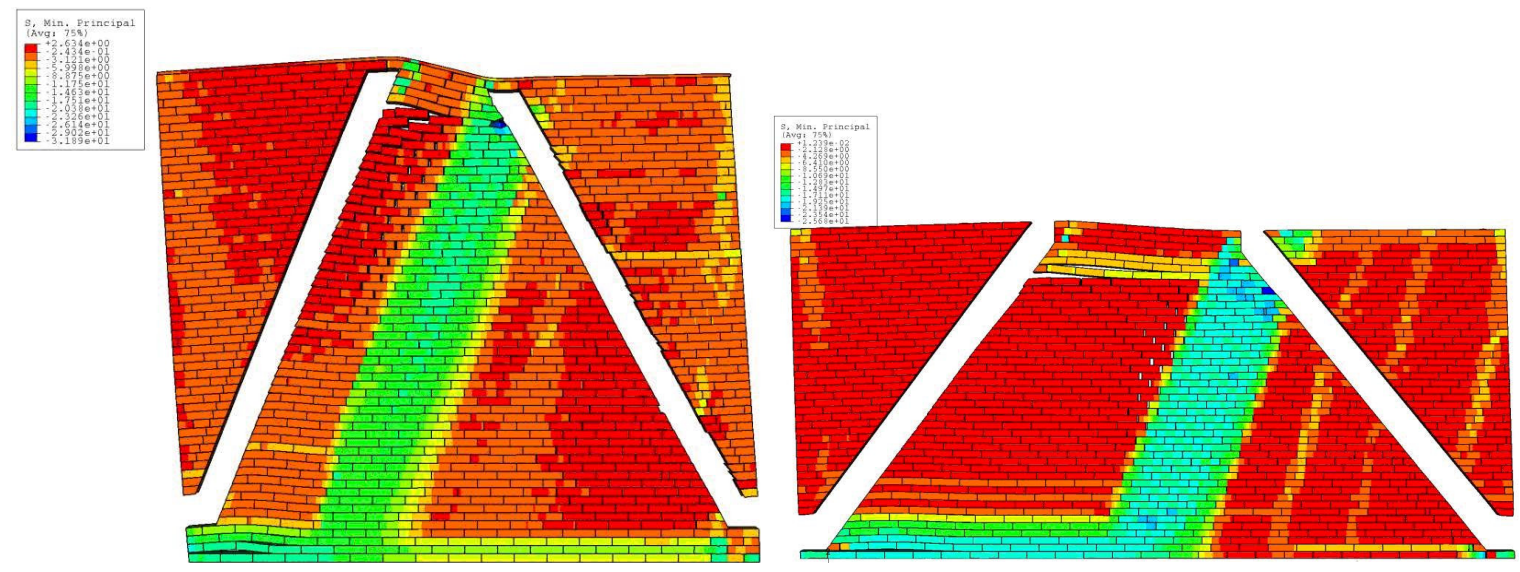

Fig. 12: Stress distribution in specimens SMS2.8, SMS3.4

Stress distribution in specimens SMS2.8, SMS3.4 is shown in Fig. 12. As it can be observed, explicit finite element analysis is capable to precisely present rational stress distribution in critical points of the wall (heel and center of wall).

\section{DISCUSSION}

Comparing the results of these models and the results of experimental tests, good agreement was observed and the ability of models to precisely simulate the behavior 
of EBFs is verified. Then the ability of explicit finite element method to present mechanical behavior and complicated geometry of masonry materials and to simulate the interaction between steel frame and masonry wall was assured. The study confirmed that such models can be used to predict crack pattern, failure modes, initial stiffness and ultimate load. In addition, explicit finite element model present rational stress distribution at critical points such as wall heel and central part of the wall. After verifying the finite element models, the influence of masonry infilled wall on the behavior of eccentrically braced frames is studied. This investigation showed that in general, the presence of masonry wall increases the yield strength and the elastic range in the force-displacement curves. But the plastic behavior of the frame is deteriorated and due to fragile behavior of masonry materials, the total system of steel frame and masonry wall has a significant strength fall when the elastic range is passed. By decreasing the plastic range, the behavior of the frame is no more ductile and so the energy dissipation of the frame with masonry wall is significantly smaller when compared to those of a steel frame without masonry wall. In the case of crack pattern and failure mode of brick panels, it can be said that for small, medium and out of plane braced large span frames, the crack pattern is in the form of the horizontal propagation of cracks. For large span frames without out of plane bracing, the main cause of the fracture of the wall is out of plane deformations. In conclusion, it can be said that the effect of masonry infilled walls should be considered in design of eccentrically braced frames.

\section{CONCLUSION}

In this study, explicit finite element method is proposed for modeling and analyzing eccentrically braced frames with masonry infilled walls. Firstly, the model of single brick wall and model of EBF with infilled wall were made and these models were analyzed by explicit finite element method.

\section{REFERENCES}

1. Popov, E.P. and K. Kasai, 1986. General behavior of WF steel shear link beams. J. Struct. Eng., 112: 362-382. http://cedb.asce.org/cgi/WWWdisplay.cgi?8600496

2. Foutch. D., 1989. Seismic behavior of eccentrically braced steel building. J. Struct. Eng., 115: $1857-1876$.

http://cedb.asce.org/cgi/WWWdisplay.cgi?8903570
3. Engelhardt, M.D. and E.P. Popov, 1989. On design of eccentrically braced frames. Earthquake Spectra, 5: 495-511. doi:10.1193/1.1585537

4. Ghobarah, A. and T. Ramadan, 1990. Effect of axial forces on the performance of links in eccentrically braced frames. Eng. Struct., 12: 106113.

linkinghub.elsevier.com/retrieve/pii/S01410296000 01000

5. Ramadan, T. and A. Ghobarah, 1991. Prediction of the ultimate capacity of wide flange link beams under cyclic loading. Comput. Struct., 40: 409-418. url:http://www2.ing.unipi.it/dis/strutturecomposte/r eport/report01-unian.pdf

6. Fukumoto Y., 1992. Stability of Beams in Eccentrically Braced Frames. Stability and Ductility of Steel Structures Under Cyclic Loading, CRC Press, Inc., USA. ISBN 0849301440, 9780849301445

7. Ricles, J.M. and E.P. Popov, 1994. Inelastic link element for EBF seismic analysis. J. Struct. Eng., 120:441-463. http://cat.inist.fr/?aModele $=$ afficheN\&cpsidt $=1119$ 5744

8. Berman, J.W. and M. Bruneau, 2007. Experimental and analytical investigation of tubular links for eccentrically braced frames. Eng. Struct., 29: 19291938. Doi:10.1016/J.Engstruct.2006.10.012

9. Dhanasekar, M., P.W. Kleeman and A.W. Page, 1985. Biaxial stress-strain relations for brick masonry. J. Struct. Eng., ASCE, 111: 1085 -1100. url:http://cedb.asce.org/cgi/WWWdisplay.cgi?8501 199

10. Middleton, J., G.N. Pande J.X. Liang and B. Kralj, 1991. Some recent advances in computer methods in structural masonry. Computer methods in structural masonry. Books J. Int. Swansea, UK., $\mathrm{v}: 4, \mathrm{pp}: 49-63$. http://linkinghub.elsevier.com/retrieve/pii/0045794 995003614

11. Gambarotta, L. and Lagomarsino S. 1997. Damage models for the seismic response of brick masonry shear walls. Part II: The continuum model and its applications. Earthquake Eng. Struct. Dyn., 26: 441-462. Doi:10.1002/(SICI)10969845(199704)26:4<441::AID-EQE651>3.0.CO;2-0

12. Moghadam, H.A. and M. Ghaemian, 2006. Experimental and analytical investigation into crack strength determination of infilled steel frames. J. Construct. Steel Res., Vol:62, Issue:12, pp:1341-1352.

url:http://www.iiees.ac.ir/English/Structure/eng_str u_staff_mohammadi.html 